\title{
THE REPUTATION OF THE MILITARY LEADER BETWEEN EGO-PERCEPTION AND GROUP PERCEPTION
}

\author{
Vasile ROMAN, Maria ROMAN \\ "Apollonia" University, Iași, Romania \\ v_roman2005@yahoo.com
}

\begin{abstract}
Any organization is in a permanent search for reputable leaders. Leaders adopt a behaviour reflected by their professional training and ego-esteem. Ego-perception reflects how a person is seen as a genre (how is?), as an identity (who is?), as an image of his/her ego (what is?), as self-opinion (what has?) and as an object (what affects?). The perception of those around them revolves around the things that are known to themselves and to the others (such as the physical reflection), the things the person knows about but the others do not know (personalities not shown), the things others know about him/her own person, but about which he/she does not know (personality traits that are perceived differently) and things that neither the person nor the others know (the ones in the unconscious). To be effective, the leader needs to know himself/herself and the environment in which he/she is acting, and to constantly pursue the relationship between ego-perception and perception of others about him/her. The desired report is the one in which the personal perception is the same as that of the others. Any significant variation leads to under or overestimation and, implicitly, to negative effects on the leadership process.
\end{abstract}

\section{Key words: leader, ego-esteem, ego-perception, personality, relationship}

\section{Introduction}

We live in a world where mercantilism has become a way of life. People tend more to what it means to have, and perhaps less to the point of being someone who sacrifices himself for the success of the others.

Organizations are constantly interested in promoting an effective image where the delivered product is declared superior to the one produced by the competition.

Constantly centred on the idea of being politically correct in promoting the working climate and the relationships with others, organizations tend to build positive images, relying on the idea that they have solved the problem of good reputation in this way.

Very often the fame that organizations and people have in the eyes of the public is considered to be a good reputation and for the simple reason that the social mechanisms they use to advertise bring only positive elements and less true reputation into attention.

Given that society tends to be regulated by rules limiting the disclosure of truths that can bother, along with the tendency of positive discrimination, their organizations and leaders lead them into a state of confusion.

Notoriety or reputation implies a public recognition of personal value, whether positive or negative, determined in particular by the relationships the individual is capable of developing in his or her living environment. 
Reputation becomes, through exploitation, a scale that the individual moves in the professional and social ascension, but it is also a gap that opens between him and the social environment, when there are clear discrepancies between what the individual displays and his characteristic reality.

We often find that the company delivers notorious products that are only handled in a packaging form, inside of which there is a characteristic and professional vacuum.

Society as a whole cannot be blamed for manipulation, but the means it makes available, whether it be mass-media or social media, can be considered if not guilty competitors, at least ignorant supporters of false models.

An empirical analysis of how leaders build their reputation leads us to two main directions, one of a clear ego-perception, and a hard work for recognized performance, and the other of an emotional exploitation of the environment to create a fake reputation.

Perhaps military leaders are not tempted to adopt the second option, for the simple reason that the environment in which they develop is a homogeneous value, but in this case the risk of distorting the mechanisms of building and measuring reputation can be perverted.

The desire to be value-recognized determines the military leader to focus his efforts on professional development, on the formation and development of the set of characteristic values and more on rigor and military discipline, convinced that his organization has this desideratum as a centre of gravity.

The new trends in the organization and functioning of organizations demonstrate that individuals feel the need to be led not only by knowledge, by acquired intelligence, but also by the presence of empathy, that is, by the presence of the emotional intelligence of the act of command.

This combination, between what individuals know that they know and can professionally express, and how they are displayed and used to motivate subordinates, require that the leader balance between what he feels and wants to be, and what subordinates think he is and, would like to be.

\section{Reputation as ego-perception}

Self-perception reflects how a person is seen as gender, identity, ego-image, egoimage, and object.

The military leader is no longer just the man who respects the anthropometric standards established by the military organization because the technological society today places more emphasis on developing the harmonious personality that demonstrates mental capacity, character and especially the ability to relate effectively to others.

The military leader, woman or man, is the one who knows who he/she is, as a physical description, has no inhibitions of height or skin colour, feels comfortable in his/her body, is pleased with his/her voice or the colour of his/her eyes.

But there is a problem when this leader has a false perception of his physical appearance by experiencing the feeling of professional non-fulfilment determined by what others have and does not have. Such a feeling leads to changes in the relational structure, isolation, frustration and, ultimately, the feeling that a value compensation can come from the use of force in relation to those of nature that have received other dimensions. In this respect one can identify manifestations of men in relation to women, marked by misogynism, of women to men, marking of misandrinity and ultimately of all against all, as forms of psychological compensation.

Defining self-identity as a component of egoperception is accomplished by the inner radiography that each individual performs. Identity is the central pillar of personality, around which the other five components (temperament, character, skills, intelligence, and creativity) are structured [1]. 
The leader identifies his ego as a personality whose conduct, affectivity, thoughts and other characteristics, relatively stable over a period of time, are unique.

Through an exhaustive analysis we find that the ego is in a possible overlap with consciousness, and therefore it is the one acquired through birth, along with attention and will. So the identity of the leader is the one that draws the map of social behaviour that will be acquired through learning, because what he thinks of his own person, along with the attention he attaches to his psycho-physical reactions and corroborated with his desire to be, develops as indicators of his consciousness. Consciousness makes the individual aware that he exists as a rational being since the world exists as a reflection of his consciousness. In lucrative terms of leadership, we can say that the correct perception of identity, developed by consciousness, traces the individual's egoless path to the performance of the organization. Consciousness places the toplevel leader of Maslow's pyramid in the category of those who need the egorealization of those who are aware of the value of professional value and advocates for its transfer within and for the efficient development of the organization.

The correct manifestation of the value of the ego becomes a determinant element in the development of the reputation because in this process the image that the organization creates to the leader as a dimension of the value contribution, but the development of the relational framework, the increase of the number of persons who wish to benefit from this contribution more the synergy of the organization's engagement in the project.

The ego cannot only have positive contributions but can also be destructive, as individual afflictions have suffered trauma at different stages of life. Permanent psychological evaluations can highlight dissociative personality disorders, but this does not mean that a mentally healthy individual cannot, under organizational stress, refute elements that the consciousness escapes from control and the unconscious, affected part displays them. Such exits are formulas whereby we can identify controlled reputation items, signs that prove a possible unsuccessful hierarchical desire.

It is not necessary for an individual to have a mental problem in order for his emotional intelligence to be reduced and his behaviour to be aloof, as it is not absolutely necessary for performance to be determined to the greatest extent by the ability to empathize with the organizational environment.

The dimension of self-image, as a defining element of notoriety, is the way we perceive our own physical, emotional, cognitive, social and spiritual characteristics. How we perceive depends on the degree of egoesteem (ego-esteem, ego-observation, and ego-acceptance) that we have [2].

The military leader is institutionally educated, perhaps differently from the civilian, to have a correct and positive perception of ego, not just because the military organization requires strong and courageous people, but also because the curricular area includes disciplines that value personal qualities.

The military leader is the type of symbiotic personality in which the physical characteristics are cultivated for the formation of the fighter, the emotion is developed for the empathic spirit and behaviour, necessary in the motivation of the subordinates, the knowledge is developed as the responsibility of the subordinates' leadership in the combat, the social component is consecrated to the subordination of the existence to protect, even at the cost of life, the independence and sovereignty of the people, and the spiritual part is divided between the belief in national values and in the military organization and those of the religious faith, independent of the institution but dependent on the will to overcome. 
The self-image depends on our own opinion about us and should not be reflected in the eyes of others, but in our eyes. Every individual is unique in the effort as it is unique in accomplishments. Every person has qualities that bring in value as defects that can affect the organization. The military leader has the ability to make his/her own assessment based on the military standards as he/she can be ranked on a step of these standards. The ability of the leader to constantly report to the standardized expectations and not to the opinions of colleagues or subordinates creates the comfort zone of ego-assessment, ego-esteem and ego-acceptance.

Self-rating can also assume risks when the institution standards are not correctly set, as ego-observation may be dangerous when benchmarks are arbitrarily set by one's own person. What is important to the military leader is the idea of ego-acceptance, that is, the idea that the individual is not a sum of defects or that defects are elements that can never be changed. Positive thinking in analysing personal defects transforms "mud" into fertile soil that contains the germs necessary to evolve.

Analysing the concept of self-opinion, we find that it is reflected in accepting defects, not just qualities, as well as the awareness of the fact that the good-evil couple exists in each individual. Self-opinion does not have degrees of comparison, but it gives a clear note of personal limits, whether physical, cognitive or emotional, of the ability to interact with others and certainly more or less real fears.

Self-esteem is a starting point for building strong motivation and can be decisive in designing future career stages. Military leaders who have the ability to self-analyse correctly realize that although at some points in the military career they are very good at tactical command positions, as they evolve strategically, the institutional requirements are not favourable and need to be adjusted to major state areas.
The military leader is not the perfect individual or person, but he is the person who, through education, realizes that good and evil coexist, that the military organization is called upon to carry out a management of violence in order to bring it well and that, if it is prepared to face such a challenge, then surely personal challenges are far inferior.

Self-perception also refers to how the individual as an object relates to what surrounds him, that is, what he finds to be a reflection of the behaviour of others in the functioning of one's own personality. Given that the individual is a social person and that his development is the reflection of social learning, that is, the influence of the environment on personality development, it is necessary to identify the elements of affection and thought that influence and affect his state of comfort.

A well-known writer says we are the sum of the books we read, but more of the people we meet, and in this respect it is necessary for the military leader to be able to discern that not everything that is offered to him is as helpful as not everything that is critical of it is destructive to selfrealization.

It is difficult to achieve a fair relationship between what we expect from the organization and what it offers us, but it is within the reach of the person to identify the causes of organizational behaviour, to understand the personality of the individuals that make up and especially the context in which they manifest themselves. Military leaders may experience certain organizational frustrations, given by regulations and hierarchy, but they must eliminate those elements of discomfort that can be given by false perceptions of people.

\section{Reputation as a result of the perception of others}

The perception of others is reflected in things that are known to one's own person and to others (like physical reflection), the things the person knows about but which 
others do not know (personality traits not shown), the things others know about his/her own person, but about which he/she does not know (personality traits that are perceived differently) and things that neither the person nor the others know (the ones in the unconscious).

The military leader is perceived both by his position in the organization and by his social status as a social model. His attitude is influenced by a number of factors such as health, living and working conditions, general hygiene, physical work and sports, understood as a functional notion as a whole and not just as an aesthetic issue. The athlete characterizes the tone and overall level of body development, muscle tone, functional status of the central and peripheral nervous system. In the same way he/she moves, a person who learns to dress properly, because proper clothing is part of the plans for the next day, anticipating the needs, or even ensuring all measures to cope with the challenges that have arisen.

The force does not only mean physical and clothing, but also the ability to demonstrate an intrinsic link between body shape and behavioural content. The way of speaking, voice tone, diction, accent and pronunciation, linguistic knowledge, classical conversation subjects, speech mistakes, corroborated with classical manners, gestures, body movements, posture and attitude give an ensemble that is analysed and perceived, in different grades, by the others.

The physical reflection of self-perception in the perception of others is not a simple phenomenon of mirroring but turns, in relation to the quality of the behavioural act, into an example to follow or in a condemnable model. The military leader is challenged to assume social manifestation rules reflecting both his military and citizen's position, desirous of working symbiotically without eclipsing one another.

The reputation of physical care is built up by knowing the expectations and organizationally, by complying with the military norms, as well as by being flexible to civil norms, by self-control effort of emotional states, and not by assimilation of models.

Unrecognized personality traits, that is, strengths and weaknesses that a person is aware of, but about whom he knows less, are elements that increase or diminish reputation if they are not processed and enunciated.

The main personality traits are morality, reason, dignity, tolerance to frustration, empathy, assertiveness, intrinsic motivation, creativity, optimism and sociability, and we can say that most of them are displayed by any person. For military leaders, who are extremely centred on the valorisation of a disciplined environment, there is a constant concern for not letting personal weaknesses go into the relationship with the organizational environment.

An empirical analysis, based on what we experience as leaders and what we observe in the routine behaviour of military leaders, brings the notion that the internalized features are moral, empathetic, assertive, and perhaps optimistic.

Morality, as a personality trait, does not enunciate but manifests the ego. The military environment, conforming to national and organizational values, does not question the idea of moral behaviour, but leaders are constantly challenged to conformations that sometimes seem immoral. War is not moral, although it complies with laws and principles, as training of militaries for violence is not a moral act, but it proves to be useful.

The morality of the leader is a little transparent, and perhaps little understood, when its manifestation must produce the effect of what is right in military action, and not what it is for social action.

The organization will not know an internalized state of the leader about moral norm, but will value its behavioural effects and add value to this reputation. 
The empathic behaviour can be considered as another internalized feature whose effects do not have a degree of visibility, either increased, or easily quantifiable. Empathy is a matter of education of emotional intelligence and its visibility can be confused with many features or with the idea of humanity. Empathy can be an element of behavioural risk when talking about violence management war and can affect the emotional state of the leader too closely associated with comrades. The empathy of a leader is measurable in the acts he undertook for the psychological comfort of his subordinates, in his concerns for their institutional well-being. The absence of this feature can also be considered as a form of individual selfprotection and it can be interpreted as a weakness for this simple reason

Analysing assertiveness, we can assume that it reflects at first instance in communication and that most military leaders tend to communicate either passively or aggressively, the behaviours acquired through the role of subordinates and then of commanders. Starting from the idea that the military institution prepares the individual for action under the pressure of the environment, it is considered that the main element of the communication is the understanding of the message and less the mood of the one who is in dialogue.

What leaders seek not to show, though often they would like, is assertive behaviour, that firm behaviour, not violating the personal psychological space of others, having self-respect and showing respect for the interlocutor. This conscious avoidance is determined by the false perception that in the relationship with the bosses it could be considered indiscipline, and in the relationship with the subordinates it could be perceived as a laissez-faire leadership style. At the same time communication is less used in the assertive dialogue, in which firmness and common sense, the expression of what we are, what we want and what we ask for in a certain situation, but without choosing the others, within the limits of common sense, could be perceived as an overflow at the limits of military communication.

Optimism as a character trait of the military leader is seen in relation to the organization, not because it is considered illusory but because it has limits in military action. Optimism is a dying and internalized element of the military leader, and because the environment in which the military is prepared to act is volatile, uncertain, ambiguous and complex, realism is preferred to the former. Optimism is an element that increases the reputation of the individual, provided it is moderate and more dominated by personal self-control. The military leader will always be attentive to the optimism used to achieve the success of military action because he is aware that too much optimism decreases vigilance in action.

If we analyse the different perceptions, namely what the organization sees in the leader and it does not perceive its ego, then the rational, motivational features of human dignity and sociability can be included in this group.

The leader's rationale is not just a question of personality, in the analytical or intuitive sense, as it is the effect of education in the military environment. In this respect, what is rational to the one who leads can be identified as less rational for the one driven. Assuming the risks along with the responsibility for the lives of the subordinates, gathered in a corollary of victory, note that the leader's reasons have different perceptions. A leader who thinks analytically can be considered fearful, can be judged less courageous just for asking for information and time. An intuitive leader, acting on a pattern of experiential patterns, can be considered as a brave person, but also as a person who does not value the organizational effort.

And motivational behaviour may have different degrees of perception on the part of the organization when the leader believes 
that personal example is the main reference. A person's reputation is appreciated when he manages to achieve a balanced relationship between people's expectations and awaited rewards. People are expect for every effort made to receive a reward, although both the society and the military institution have created the organizational framework for the remuneration of the effort. However, there is an intrinsic need for behavioural strengthening, in which the individual does not fall in routine, requires emotional formulas to recognize the importance of his work. Deprivation and excess rewards can influence the organization's perception of the leader's personality and may also create a false image of the organization.

Sociability, as a personality trait, is given by two important elements, the first being the introversion-extraversion ratio, the difficulty to model ratio, and the second by the rigors of organizational discipline. An introverted leader, though characterized by a harmoniously developed personality, not so willing to display his feelings and emotions, and not prepared to listen to others, may be perceived by the organization as less involved in the organisational life. At the same time, an extraverted person, who does not explain such behaviour, can be considered as interested in the emotional exploitation of the organization.

It is not meaningless to analyse the sociability of the military environment, centred on hierarchy and discipline, limiting informal relations, which can jeopardize the reputation of both the leader and the organization if used excessively. The tendency to strictly observe a communication hierarchy, along with the inability to understand the boundaries of informal relationships, can be organizational destruction, with disciplinary relaxation, with the development of informal relationships that go beyond the organizational framework and can become real dangers for the correct perception of the degree of notoriety of the leader.

Going to the last class of perceived elements of the organization in relation to the leader, I think that the dimensions of personality that neither the individual nor the organization knows about are, in my opinion, the unconscious, dignity and tolerance to frustration.

Human dignity is closely linked to the feeling of honour, self-esteem and respect for others. Military honour as a reflection of human dignity presupposes conscious assumption, voluntary practice, and bringing into an unconscious mechanism the behaviour of a set of values centred on honesty, fairness, patriotism, courage and sacrifice.

Both the military leader and the organization are acting almost unconsciously to perpetuate a wretched honour and reputation of the military institution. Considering their own person as playing a second role, sacrificing time, energy and emotions, the soldiers act unconsciously so that the perennial values, the history, the present, the success and the image of the military institution will develop in value.

If military honour requires and cultivates a set of common values that are assumed personally, then the military environment creates the opportunity of their manifestation in peace, crisis and war, The degree of pressure the military institution is subjected to creates not only the framework for capitalizing on human qualities, but also an uncomfortable feeling, such as stress and frustration.

Frustration is not defined as an obstacle, because in reality nothing allows us to know what will be appreciated as such by the subject. One and the same situation can be perceived as favourable by a person and can be experienced as frustrating by another. Low tolerance to frustration is directly related to both the habit of claiming too much and deeply negative ideas, but it has several short-term benefits, such as 
increased convenience at the moment, and disadvantages, ranging from annoyance, resentment and depression, to increased frustration in the future and offering a negative model to the others.

Militaries are educated and trained to resist organizational stress, but the tolerance to the frustration of this environment is individual and has different degrees and therefore, subconsciously, most will seek to identify themselves in the leader's behaviour.

\section{Conclusions and recommendations}

Professional reputation is undoubtedly related to continuing education and training in the organizational environment, and moreover can be developed by the organization's memory.

The reputation of a leader is the harmonious reflection of self-perception in the perception of the members of the organization, intrinsically linked to his/her own perception of the organization.

A leader's reputation cannot be constructive if self-perception has a lower limit than the organizational one, here including a low self-esteem, as it cannot be far superior to the organizational one, here involving an over-estimation of personal ego.

The ability of the leader to identify weaknesses and to develop them through the organization's contribution, along with the ability to identify false organizational perceptions about themselves and to change them ultimately leads to a greater degree of reputation.

Strong personality traits do not help the harmonious development of the relationship between the military leader and the organization for the simple reason that they can reflect a certain degree of selfish interest for visibility.

Assessing the combination of behaviour and personality can have a credible effect, the intention of this assessment being not only to communicate the perceptions of others to them, but also to help leaders to understand their own personality in their behaviour.

Conscious leaders understand the preferences and predispositions that allow them to control their behaviour and, by doing so, become more effective. Arguments of this kind form the basis of the contingency theories that suppose the leader can modify his/her own behaviour to be more appropriate to a particular context. Understanding the roles and behaviours required for performance at each organizational level is critical to individual efficiency.

\section{References \\ [1] Moştoflei Constantin, Duţu Petre, Liderul militar în România, "Carol I" National Defense University Publishing House, 2007. \\ [2] Johns, Gary, Comportament organizational, EcoNUmica Publishing House Bucharest, 1998.}

